\title{
Effect of Si content on machinability of Al-Si alloys
}

\author{
B. Akyüz \\ Department of Mechanical and Manufacturing Engineering, Bilecik Seyh Edebali University, 11200 Bilecik, Turkey
}

Received 4 June 2015, received in revised form 29 December 2015, accepted 10 November 2016

\begin{abstract}
This study investigates the effect of the change in the amount of Si found in Al-Si alloys on mechanical properties and machinability properties of the alloy. The way the microstructure and the mechanical properties change depending on the increase in the $\% \mathrm{Si}$ amount in the alloy and the effects of such changes on Flank Build-up (FBU), wear in the cutting edge, surface roughness, and machinability were analysed. To this end, alloys with varying amounts of silicon (i.e., 2 to $12 \mathrm{wt} . \% \mathrm{Si}$ ) were used in the study. Experimental samples were obtained by casting in sand moulds. It was observed in the study that, in Al-Si alloys, the mechanical properties and machinability of alloys increased depending on the rise in \% Si in the alloy, that cutting forces decreased, and accordingly, machinability increased. It was also observed in the study that the increase in the \% Si amount raised the surface quality (decrease in surface roughness).
\end{abstract}

Key word s: machining, cutting force, mechanical properties, Al-Si alloys

\section{Introduction}

Today, aluminium alloys are commonly used in numerous industries, predominantly in automotive, transport, aviation, and aerospace industries [1-8]. In addition to aluminium alloys being plentiful in nature, their facility to produce, machine, and mould, being lightweight and their improvable mechanical properties also increase the place of use and importance of these alloys even more in today's industries [9-12].

Aluminium alloys are quite important materials used in the manufacturing of various parts predominantly in automotive, transport, aviation, and aerospace sectors in order to lower emissions that are harmful to the environment $\left(\mathrm{SO}_{x}, \mathrm{CO}_{2}\right.$, and $\mathrm{NO}_{x}$ emissions) and to use energy resources efficiently through weight decrease $[2,3-6]$.

Within this scope, among the significant aluminium alloys most commonly used in today's industries are aluminium-silicon (Al-Si) alloys $[4,7,8$, 10]. It is observed that the studies conducted on aluminium alloys generally focus on such subjects as microstructure analysis, porosity formation, ageing characteristics, mechanical properties, roughness, and creep characteristics analysis. As a result of our liter- ature reviews, studies that investigate the effect of the change in \% Si amount in Al-Si alloys on cutting forces (machinability) and that also analyse wear on cutting edge and Flank build-up (FBU) are non-existent.

$\mathrm{Al}-\mathrm{Si}$ alloys containing $\% \mathrm{Si}$ at variable rates (that include silicon at rates ranging from 2 to $12 \%$ ) were used in this study. In the study, the effects of the change in \% Si amount on microstructure, XRD, mechanical properties, cutting forces (machinability), chip formation, wear on the cutting edge, and Flank Build-Up (FBU) were investigated. Within this scope, this study bears an original quality.

\section{Experimental procedure}

\subsection{Microstructural, XRD, and mechanical properties}

Al-Si alloys containing $\mathrm{Si}$ at variable rates (from 2 to $12 \% \mathrm{Si}$ ) were used in the experimental study. Experimental samples were obtained by casting in sand moulds. In obtaining the experimental samples, pure aluminium (Al-8E, 99.8\%) and eutectic Etial 140 alloy with $12.5 \%$ Si content $(12.5 \% \mathrm{Si}, 0.6 \% \mathrm{Fe}, 0.4 \%$

*Corresponding author: tel.: +90 22821415 42; fax: +90 22821412 22; e-mail addresses: birol.akyuz@bilecik.edu.tr, birolakyuz@gmail.com 
Table 1. Chemical composition of the studied Al-Si aluminium alloys (in wt.\%)

\begin{tabular}{lrcccccc}
\hline Alloys & $\mathrm{Si}$ & $\mathrm{Zn}$ & $\mathrm{Mn}$ & $\mathrm{Cu}$ & $\mathrm{Fe}$ & $\mathrm{Al}$ \\
\hline Al-2\%Si & 2.14 & 0.02 & 0.01 & 0.01 & 0.04 & Rest \\
Al-4\%Si & 4.12 & 0.02 & 0.01 & 0.01 & 0.04 & Rest \\
Al-8\%Si & 8.32 & 0.02 & 0.01 & 0.01 & 0.04 & Rest \\
Al-12\%Si & 11.50 & 0.02 & 0.01 & 0.02 & 0.05 & Rest \\
\hline
\end{tabular}

$\mathrm{Mn}, 0.1 \% \mathrm{Cu}, 0.1 \% \mathrm{Zn}, 0.1 \% \mathrm{Mg}, 0.1 \% \mathrm{Ni}, 0.1 \%$ $\mathrm{Ti}, 0.1 \% \mathrm{~Pb}$ content) were used. Melting processes were carried out in an induction furnace $(35 \mathrm{KW} \mathrm{In-}$ ductotherm). For the casting of samples, when molten metal reached the temperature of $\sim 720^{\circ} \mathrm{C}$, it was kept at this temperature for $30 \mathrm{~min}$ and then was cast in sand moulds. Sand moulds were prepared by adding $2.5 \%$ sodium silicate (water glass) resin to dry silica sand of 90-110 AFS grain thickness. This blended sand was mixed in a mixer, and then moulds were obtained by hardening with the prepared $\mathrm{CO}_{2}$ after the mould gap of the sand was given shape. Moulds were designed so as to obtain 4 cylindrical samples in each mould for casting the experimental samples. At the end of casting, at least 12 cast samples were obtained from each of the alloys. The diameter of experimental samples taken from the mould was $24 \mathrm{~mm}$, and length was $200 \mathrm{~mm}$. In order to modify primer Si crystals with sharp corners that might occur due to fast cooling in the mould during the casting of Al-Si alloy (eutectic) containing $12 \% \mathrm{Si}$, phosphor bronze $\left(\mathrm{CuSn}_{5}\right)$ was added to molten alloy at ppm level $(20 \mathrm{~g}$ in $0.002 \mathrm{~g} / 7400 \mathrm{~g}$ pot). Mould filling time of casts was established as 8-10 s. Chemical compounds of Al-Si alloy experimental samples used in the experiment are given in Table 1.

In the experimental study, 5 samples (with a diameter of $15 \mathrm{~mm}$ and a thickness of $10 \mathrm{~mm}$ ) were prepared from each series to be used in microstructure analysis of Al-Si alloys. Sample surfaces were cleaned by sanding (with emery papers starting from 200 grits up to 1200). Surfaces of samples used in microstructure analysis were polished with diamond abrasives $(6$, 3 , and $1 \mu \mathrm{m}$ diamond paste, respectively). Surfaces of samples were etched (for 20-25 s) with the prepared etching solution (Keller solution $2 \% \mathrm{HF}, 3 \% \mathrm{HNO}_{3}$, $\left.95 \% \mathrm{H}_{2} \mathrm{O}\right)$. Microstructural surveys were conducted on the metallographic samples by optical microscopy (LV150 Nikon Eclipse). The hardness values of the samples were determined by the Vickers hardness test $(\mathrm{HV})$ with a load of 0.1 and $10 \mathrm{~N}$ by using microhardness tester (Shimadzu HMV-2). At least ten hardness measurements were carried out on each sample.

Tensile tests were carried out. Data on the tensile strength of alloys (Ultimate Tensile Strength UTS) and elongation \% (El\%) values were obtained from tensile tests. Samples used in the tensile tests were prepared in compliance with ASTM E 8 M-99

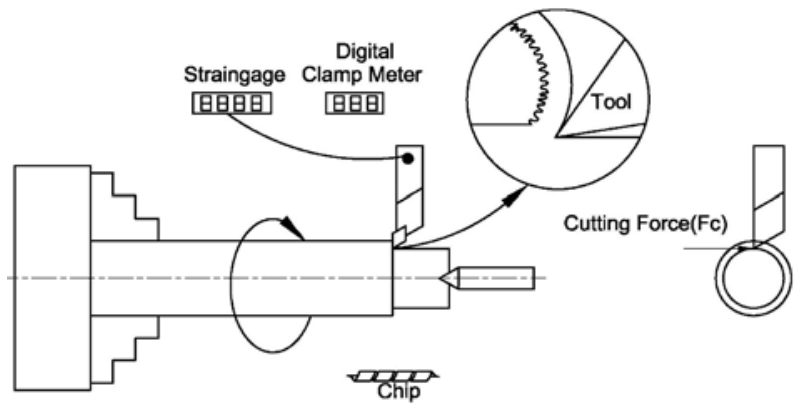

Fig. 1. Schematic representation of experimental set-up with strain.

standards. Tensile tests were carried out at room temperature $\left(20^{\circ} \mathrm{C}\right.$ ) (Shimadzu Autograph AGS-J $10 \mathrm{kN}$ Universal Tester). Tensile test data were established by averaging the 5 samples. The strain rate used for tensile testing was $1.1 \times 10^{-3} \mathrm{~s}^{-1}$.

XRD (X-ray diffraction analysis) (Panalytical-Empyrean) was carried out under $\mathrm{Cu} \mathrm{K} \alpha$ radiation with an incidence beam angle of $2^{\circ}$. The microstructure of the samples was examined using optical microscopy (OM) and scanning electron microscopy.

\subsection{Machining properties}

Machinability tests were carried out on CNC turning lathe (2.2 KW Boxford 250). Turning procedures were conducted under dry machining conditions by using Polycrystalline Diamond (PCD) (Taegutec CCGT 120408 FL K10) cutting edge and by the orthogonal cutting method. Data on cutting forces established in the study were obtained by measuring with a specially designed and produced strain-gauge (Fig. 1).

In machinability experiments, changes in the cutting speeds were measured (by keeping the chip section fixed) at varying cutting speeds of Al-Si alloys Data on the machinability of alloys based on the changes in cutting forces were prepared in graphics. Data on surface roughness values, $R a(\mu \mathrm{m})$ formed depending on the changes in alloy properties and machining parameters (Mitutoyo SJ210) were obtained. Before commencing the machinability experiments, cylindrical turning procedure was carried out in order to clean the surfaces of samples. After the sample surfaces had been cleaned, (following the pre-cleaning 

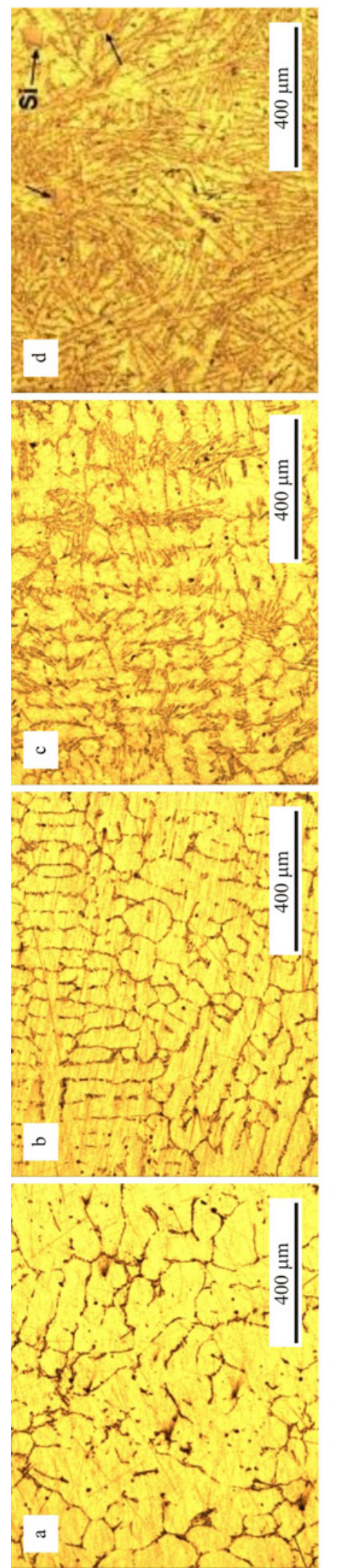

$$
\text { in }
$$
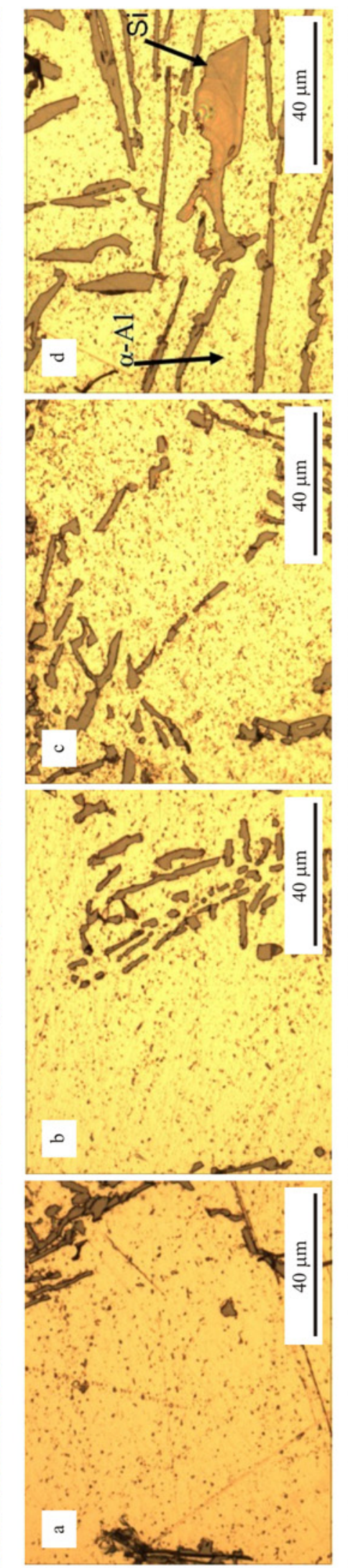

¿̌
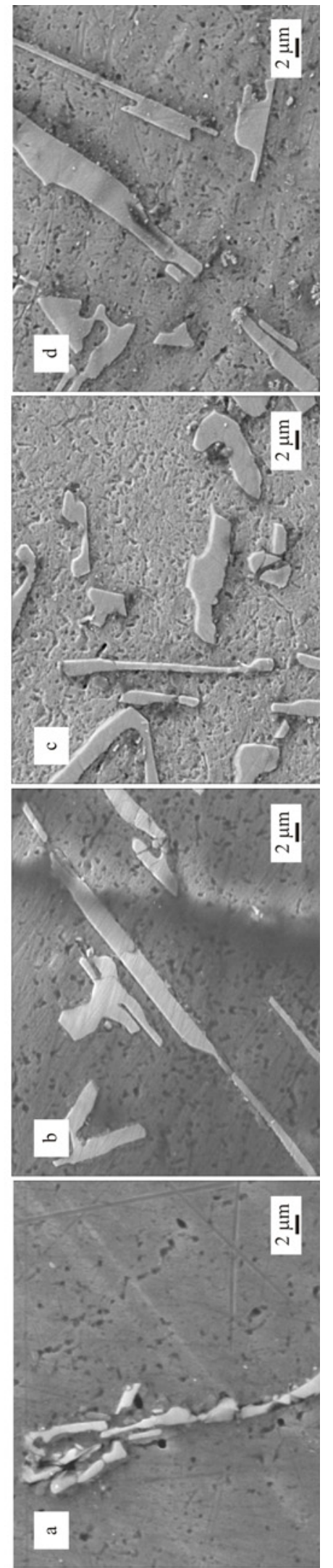

$\sum_{\text {恧 }}$ 
Table 2. Machining parameters and conditions used during the test

\begin{tabular}{|c|c|c|c|c|c|}
\hline Operations & \multicolumn{5}{|l|}{ Turning } \\
\hline Feed rate, $f\left(\mathrm{~mm} \mathrm{rev}^{-1}\right)$ & \multicolumn{5}{|l|}{$0.10($ constantly $)$} \\
\hline Depth of cut, DoC (mm) & \multicolumn{5}{|l|}{0.5} \\
\hline Cutting speed $\left(\mathrm{m} \mathrm{min}^{-1}\right)$ & \multicolumn{5}{|l|}{$56,112,168$} \\
\hline Cutting \& coolant & \multicolumn{5}{|c|}{ Orthogonal, dry cutting } \\
\hline Workpiece materials & \multicolumn{5}{|c|}{ Al-Si aluminium alloys (from 2 to $12 \% \mathrm{Si}$ ) } \\
\hline Cutting tool & \multicolumn{5}{|c|}{ Taegutec CCGT 120408 FL K10 } \\
\hline & $\alpha$ & $\lambda$ & $\varepsilon$ & $\kappa$ & $r_{\varepsilon}$ \\
\hline & $7^{\circ}$ & $0^{\circ}$ & $80^{\circ}$ & $50^{\circ}$ & $0.8 \mathrm{~mm}$ \\
\hline
\end{tabular}

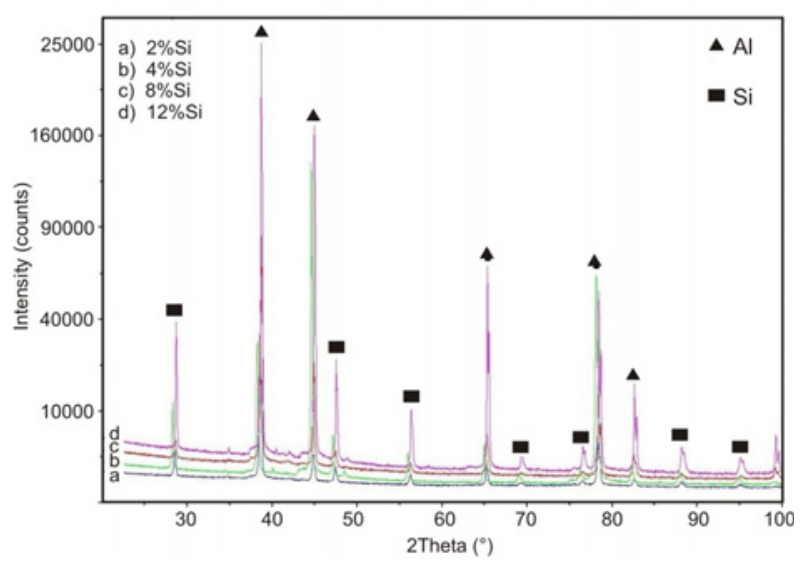

Fig. 3. XRD patterns of Al-Si alloys.

chip was removed by decreasing the diameter of samples from 24 to $20 \mathrm{~mm}$ ) experiments for measuring cutting forces were conducted. In machinability experiments, the feed rate was kept fixed $\left(0.10 \mathrm{~mm} \mathrm{rev}^{-1}\right)$. Machining parameters used in the experimental study are given in Table 2 .

\section{Experimental results and discussion}

\subsection{Microstructural, XRD, and mechanical properties}

Microstructure images of Al-Si alloys used in the study can be found in Figs. 2a-d. When examining Figs. 2a-d, it was observed that the silicon in microstructure was distributed inside the structure, and became significant/increased (Fig. 2d) depending on the $\% \mathrm{Si}$ amount in the alloy. In Fig. 3, XRD pattern belongs to Al-Si alloys. Microstructure images and XRD pattern obtained in this study are in compliance with the literature $[1,8-11,13]$.

Data on mechanical properties of Al-Si alloys used in the experiment can be observed (Figs. 4 and 5). When checking the hardness values of the analysed

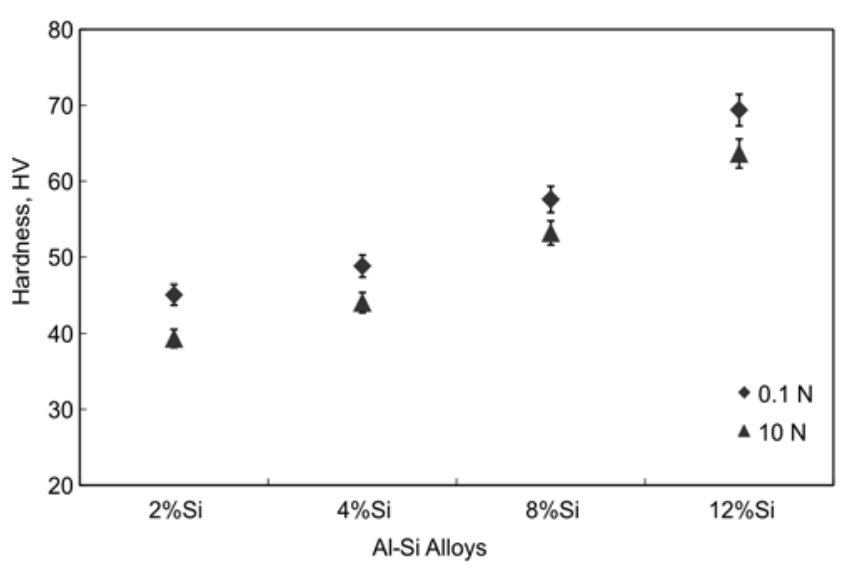

Fig. 4. Hardness (HV) of Al-Si alloys.

alloys, hardness was observed as in the order of a gradual increase from Al-Si containing $2 \%$ Si to Al-Si alloy containing $12 \% \mathrm{Si}$ (Fig. 4). While the lowest hardness value was obtained for Al-Si alloy containing $2 \% \mathrm{Si}$ as $39.3 \mathrm{HV}$, the highest hardness value was obtained as $63.6 \mathrm{HV}$ for the Al-Si alloy containing $12 \% \mathrm{Si}$. Depending on the increase in $\mathrm{Si}$ amount in the alloy, an increase $(\sim 62 \%)$ was observed in the hardness of the alloy containing $12 \% \mathrm{Si}$ (compared to the alloy containing $2 \% \mathrm{Si}$ ). The reason for the alloy to manifest an increase in hardness depending on the amount of $\% \mathrm{Si}$ in the alloy was believed to be the effect of $\mathrm{Si}$ observed/found in microstructure depending on the addition of $\mathrm{Si}$.

In the conducted experimental study, data obtained from tensile tests of Al-Si alloy samples are observed on the graph in Fig. 5. As can be observed from the graph, UTS values increased depending on the rise in $\mathrm{Si}$ amount in the alloy. However, El\% decreased.

\subsection{Machining properties}

In the conducted machinability experiments, chip section was kept fixed at different cutting speeds and 

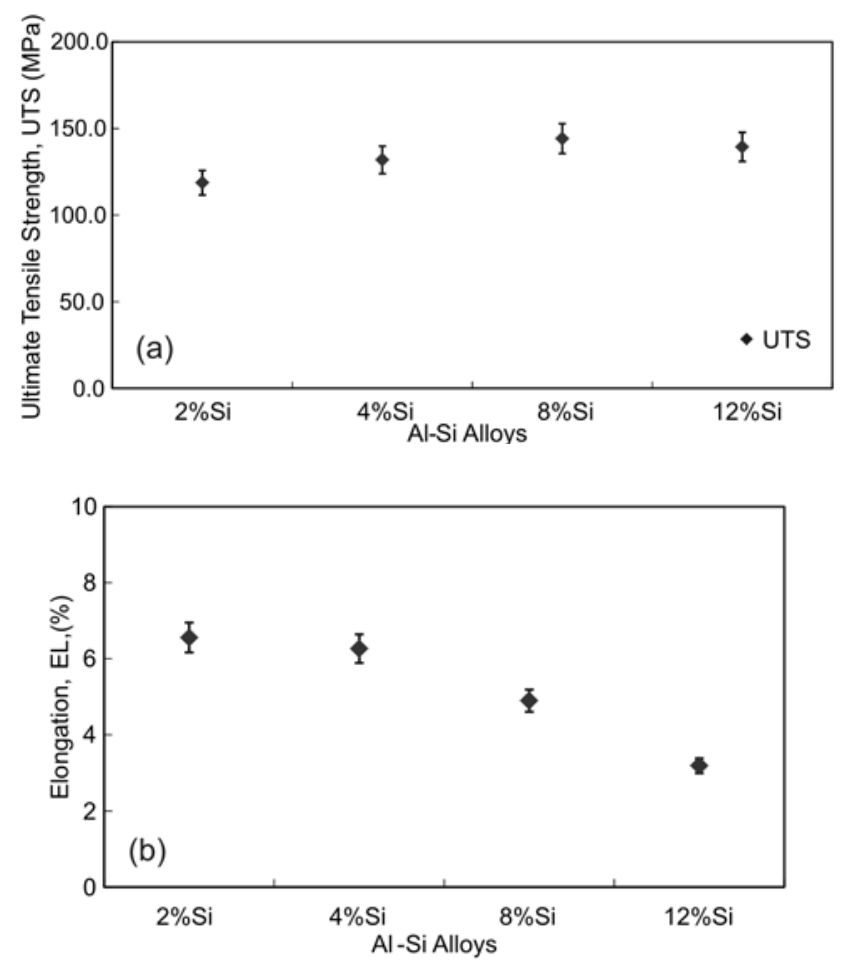

Fig. 5. Tensile tests of Al-Si alloys: (a) UTS and (b) \%El.

thus data on cutting forces of Al-Si alloys were obtained (Fig. 6). It was observed in the study that machinability of alloys increased depending on the increase in \% Si amount in the alloy (Fig. 6). In the experiment, it was found that cutting forces at lower cutting speeds were higher and that cutting forces decreased depending on the increase in $\% \mathrm{Si}$ amount in the alloy (Fig. 6). While the highest cutting force value in machinability experiments (at all cutting rates) was obtained from $\mathrm{Al}-\mathrm{Si}$ alloy containing $2 \% \mathrm{Si}$, the lowest cutting force value (at all cutting rates) was found in the Al-Si alloy containing $12 \% \mathrm{Si}$ (Fig. 6). Cutting forces (at all cutting rates) were ordered in a gradual decrease starting from Al-Si alloy containing $2 \% \mathrm{Si}$ down to the alloy containing $12 \% \mathrm{Si}$ (Fig. 6). While the cutting force value was measured as $45 \mathrm{~N}$ in Al-Si alloy containing $2 \% \mathrm{Si}$ at the lowest cutting rate (at $56 \mathrm{~m} \mathrm{~min}^{-1}$ ), it was measured as $27.1 \mathrm{~N}$ in $\mathrm{Al}$ alloy containing $12 \% \mathrm{Si}$. With the increase in cutting rate (to $168 \mathrm{~m} \mathrm{~min}^{-1}$ ), it was measured as $34.9 \mathrm{~N}$ cutting force in Al-Si alloy containing $2 \% \mathrm{Si}$ and as $19.9 \mathrm{~N}$ cutting force in Al-Si alloy containing $12 \% \mathrm{Si}$. Therefore, when comparing the machinability of alloys containing 2 and $12 \% \mathrm{Si}$, an increase $(\sim 60 \%)$ was observed in the machinability of an alloy containing $12 \% \mathrm{Si}$.

The decrease in cutting forces depending on the rise in the \% $\mathrm{Si}$ amount in alloy manifests the effect of $\mathrm{Si}$ in the alloy. Depending on the $\mathrm{Si}$ amount in the alloy, it may be noted that silicon observed in the microstructure becoming significant/increasing facilitated chip breaking [9-14] thus showed an impact in the form of a decrease in cutting forces. From this point of view, it may be noted that the machinability of alloy increased depending on the rise in $\mathrm{Si}$ amount in Al-Si alloys. Cutting forces were also observed as higher at lower cutting rates. The reason for this was the build-up of chips as a result of dislocation build-up at lower cutting rates (deformation hardening/work hardening) [15-20].

Data on the surface roughness of alloys used in the experiment are presented in Fig. 7. Surface roughness values were ordered manifesting a decrease beginning from the alloy containing $2 \% \mathrm{Si}$ down to Al-Si alloy containing $12 \% \mathrm{Si}$. It was observed in the study that surface roughness values decreased (finer surfaces were obtained) depending on the rise in $\mathrm{Si}$ amount in

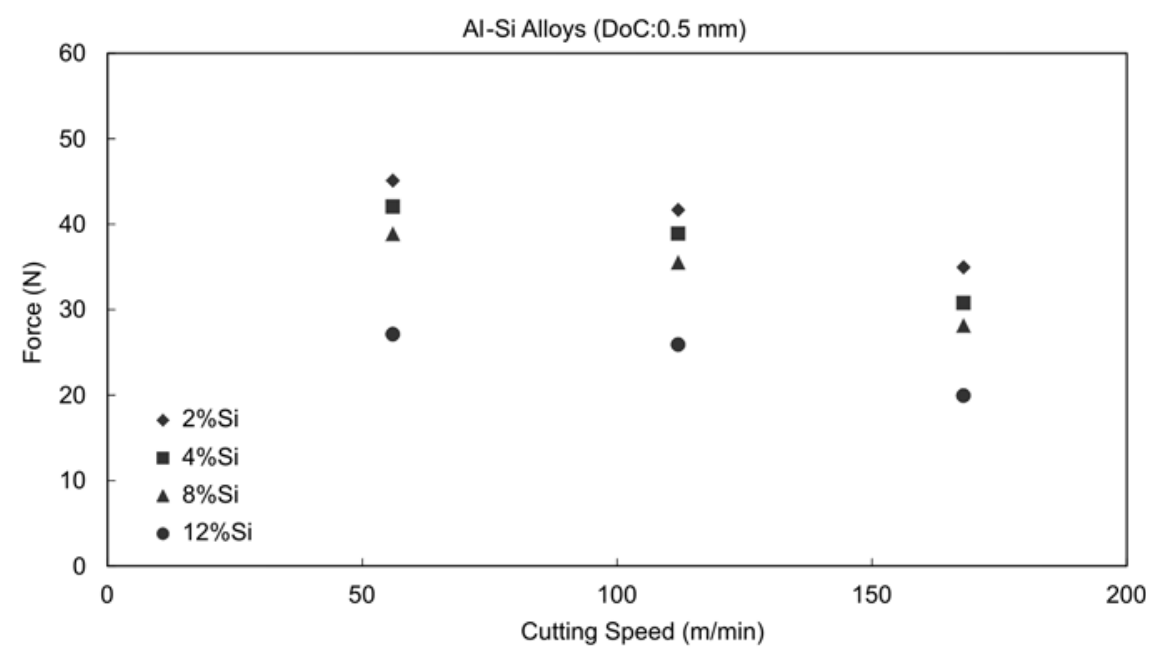

Fig. 6. Relationship between cutting forces and Al-Si alloy compositions (DoC $=0.5 \mathrm{~mm}, f=0.10 \mathrm{~mm} \mathrm{rev}^{-1}$ ). 


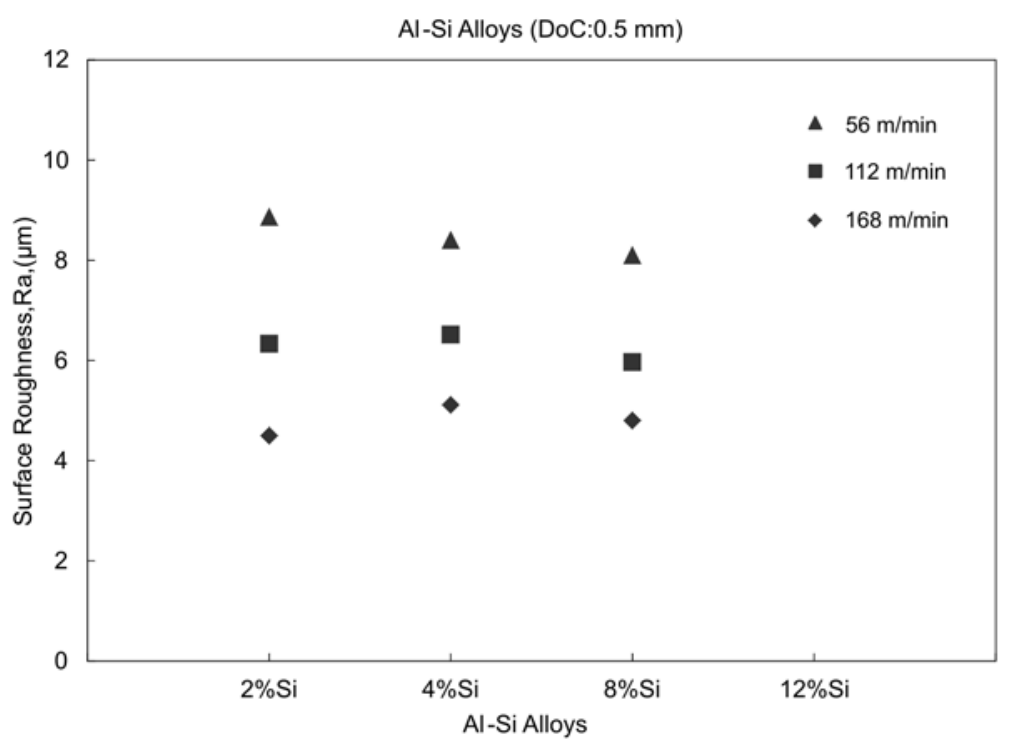

Fig. 7. The relationship between surface roughness and cutting speeds of Al-Si alloys (DoC $=0.5 \mathrm{~mm})$.
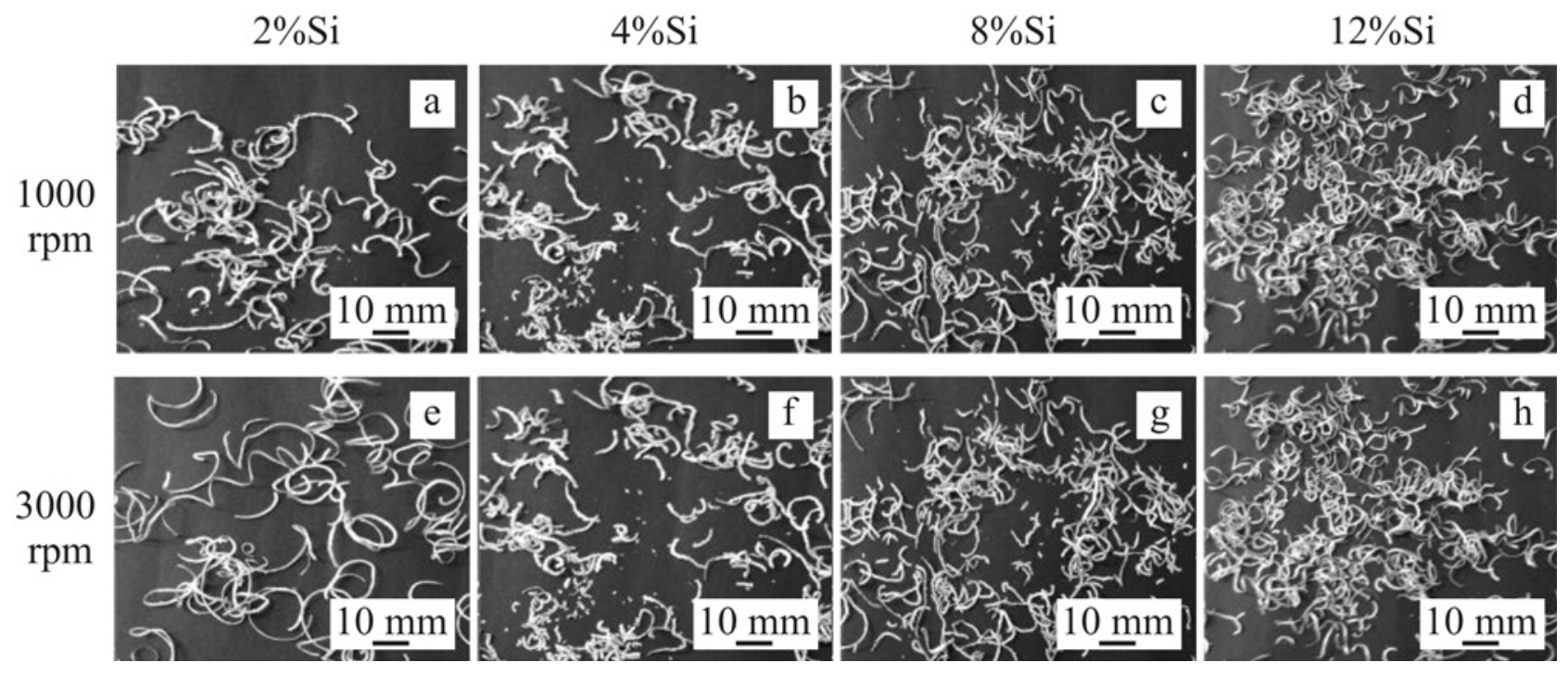

Fig. 8. Chip formation of Al-Si alloys $\left(V_{\mathrm{c}}=56-168 \mathrm{~m} \mathrm{~min}^{-1}\right.$, DoC $\left.=0.5 \mathrm{~mm}, f=0.10 \mathrm{~mm} \mathrm{rev}^{-1}\right)$.

Al-Si alloys (from 2 to $12 \% \mathrm{Si}$ ) and on the increase in cutting rate.

When examining chips obtained from processing the samples (Fig. 8), chip length changed depending on the Si amount in the alloy and on the rise in cutting rate. It was observed that Si found in microstructure was effective in chip formation depending on the increase in the \% $\mathrm{Si}$ amount in the alloy. When comparing chips obtained from Al-Si alloy containing $12 \% \mathrm{Si}$ with others, chips were observed as formed at shorter lengths (showing brittle breaking behaviour and discontinuous chip formation) as a result of chips manifesting more brittle/fragile behaviour (thanks to $\mathrm{Si}$ ) due to alloy being harder. From this point of view, it may be noted that the increase in $\mathrm{Si}$ amount in $\mathrm{Al}-\mathrm{Si}$ alloys affects chip length to be shorter.

Images of the surfaces of cutting edge used in the experiment are presented in Fig. 9. Flank Build-up (FBU) was observed on cutting edge surfaces due to dry adhesion between the workpiece and cutting edge surface (Fig. 9). It was observed that this build-up (FBU) was more on the cutting edge belonging to Al-Si alloy containing $2 \% \mathrm{Si}$ and that it spread more broadly on a continuous chip surface (Fig. 9a). In the alloy containing $12 \% \mathrm{Si}$, chip build-up (FBU) was observed as lower, however, wear occurred at the tip more and was deeper (Fig. 9h). FBU was observed to occur on the tip surface of the cutting edge from the wider surface towards the narrower surface depending on the increase in \% Si amount in the alloy (Fig. 9). A 

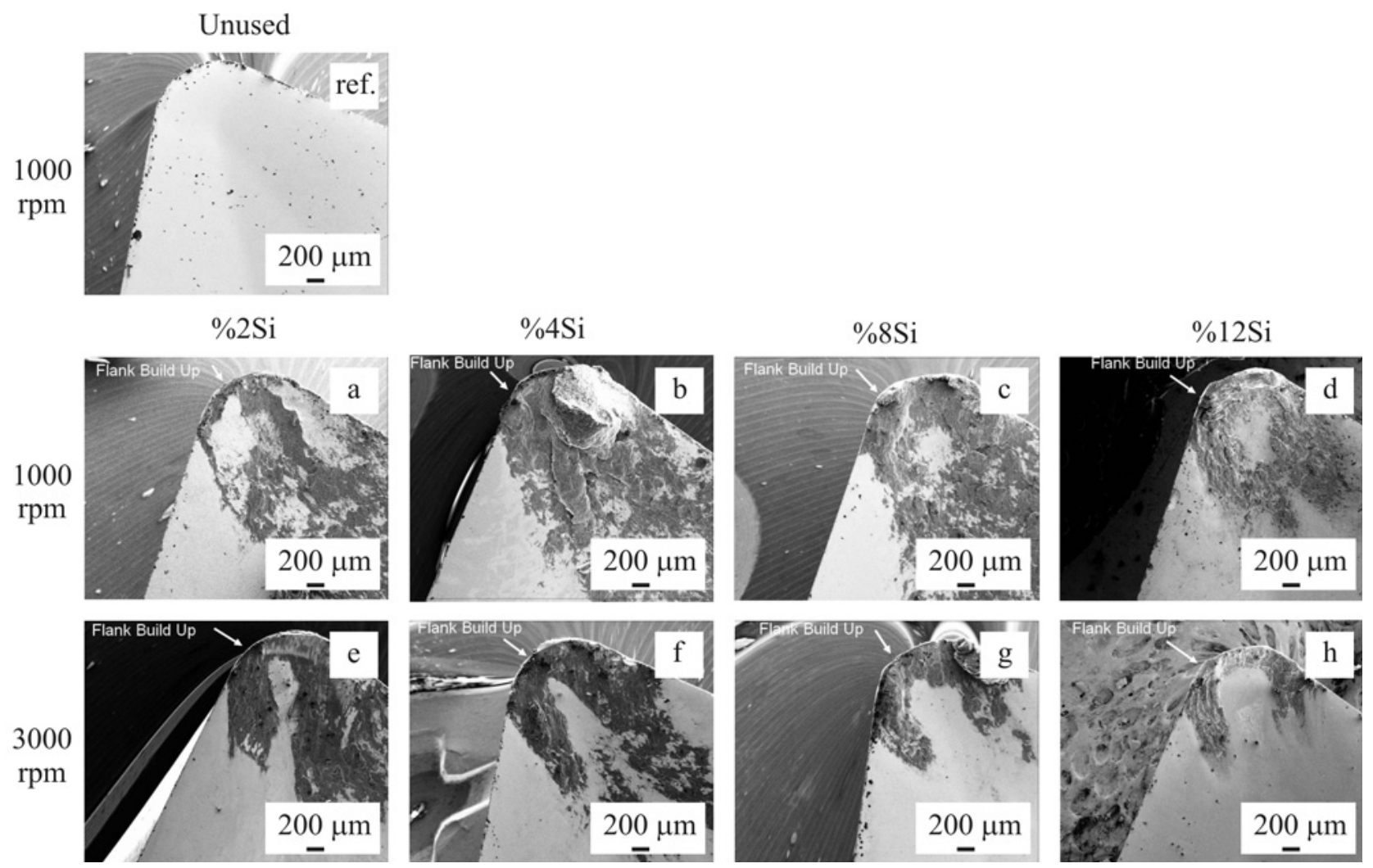

Fig. 9. SEM image of cutting tool tip used for machining of Al-Si alloys $\left(V_{\mathrm{c}}=168 \mathrm{mmin}^{-1}\right.$, DoC $=0.5 \mathrm{~mm}, f=$ $\left.0.10 \mathrm{~mm} \mathrm{rev}^{-1}\right)$.

similar case occurs due to a rise in the cutting rate.

In the experimental study, mechanical properties and machinability of alloys were observed to increase depending on the \% Si amount in Al-Si alloys (Figs. 4$6)$. It was found that chip breaks were facilitated and that this showed an effect in the form of a decrease in cutting forces thanks to the rise in \% $\mathrm{Si}$ in alloy (due to the effect of $\mathrm{Si}$ ). Especially in Al-Si alloy containing $12 \% \mathrm{Si}$, occurrence of lower cutting force shows that $\mathrm{Si}$ in the structure has a positive effect on the machinability of Si [13-15].

It was observed that cutting forces were greater at lower cutting rates. The reason for cutting forces being greater at lower cutting rates may be noted as chip build-up (FBU) adhesion on cutting edge due to an increase in dislocation build-up (deformation hardening/work hardening effect) [15-17] and local heating due to friction. From this point of view, Si presence in $\mathrm{Al}-\mathrm{Si}$ alloys (increase in \% $\mathrm{Si}$ amount) shows an effect in the form of decreasing cutting forces and machinability increases depending on the former.

It was observed in the study that a rise in $\mathrm{Si}$ amount in Al-Si alloys had a positive effect on mechanical properties and machinability properties of the alloy. Data obtained from the previous sections of the study (Figs. 2-5) and data obtained from the mechanical test results (Figs. 6-9) machinability section sup- port each other. Data obtained from the study are in compliance with the literature [1-14].

\section{Conclusions}

The below-mentioned results were obtained from the experimental study:

- Mechanical properties of alloys were observed as increased depending on the $\% \mathrm{Si}$ amount in $\mathrm{Al}-\mathrm{Si}$ alloys used in the experiment. On the other hand, El\% decreased.

- It was observed that the increase in \% $\%$ i amount in the alloy ( $\mathrm{Si}$ observed in microstructure becoming significant) had an effect in the form of a decrease in cutting forces. Machinability of alloy increased depending on the decrease in cutting forces.

- Cutting forces were observed as higher at lower cutting speeds. Cutting forces were observed to decrease along with the increase in cutting speed. The highest cutting force was found to occur in the alloy containing $2 \% \mathrm{Si}$.

- In alloy, surface roughness values were observed as on a decrease (finer surfaces) inversely due to an increase in Si amount in the alloy. Surface roughness values were observed as higher (rougher surfaces were formed) at lower cutting speeds. 
- The increase in \% $\mathrm{Si}$ amount in alloy was observed to have an effect on chip formation. Chips were observed to form at shorter lengths depending on the increase in \% $\mathrm{Si}$ amount in alloy and cutting speed. Chips were observed to form at shorter lengths in Al-Si alloy (containing $12 \% \mathrm{Si}$ ) at higher hardness due to the effect of silicon chips formed at longer lengths in $2 \% \mathrm{Si}$ alloys.

- It was observed that the increase in Si amount affected Flank Build-up (FBU) formation on cutting tool edge and on cutting forces formation. It was observed that FBU spread on the cutting edge surface at lower cutting speeds and that FBU formation was higher in Al-Si alloy containing $2 \%$ Si that had higher ductility.

\section{References}

[1] Shi, W. X., Gao, B., Tu, G. F., Li, S. W.: Journal of Alloys and Compounds, 508, 2010, p. 480. doi:10.1016/j.jallcom.2010.08.098

[2] Mohamed, A. M. A., Samuel, A. M., Samuel, F. H., Doty, H. W.: Materials and Design, 30, 2009, p. 3943. doi:10.1016/j.matdes.2009.05.042

[3] Ogawa, T., Haruyama, S., Era, H., Kishitake, K.: Materials Transactions, 46, 2005, p. 1771. doi:10.2320/matertrans.46.1771

[4] Onyia, C. W., Okorie, B. A., Neife, S. I., Obayi, C. S.: World Journal of Engineering and Technology, 1, 2013, p. 9. doi:10.4236/wjet.2013.12002

[5] Roy, P., Sarangi, S. K., Ghosh, A., Chattopadhyay, A. K.: Int. Journal of Refractory Metals \& Hard Materials, 27, 2009, p. 535 . doi:10.1016/j.ijrmhm.2008.04.008.

[6] Guru, P. R., Kan, M. D. F., Panigrahi, S. K., Ram, G. D. J.: Journal of Manufacturing Processes, 18, 2015, p. 67. doi:10.1016/j.jmapro.2015.01.005
[7] Hu, X., Ai, F., Yan, H.: Acta Metall. Sin. (Engl. Lett.), 25, 2012, p. 272.

[8] Zedan, Y., Samuel, F. H., Samuel, A. M., Doty, H. W.: Journal of Materials Processing Technology, 210, 2010, p. 245. doi:10.1016/j.jmatprotec.2009.09.007

[9] Saravanan, R., Sellamuthu, R.: Procedia Engineering, 97, 2014, p. 1348. doi:10.1016/i.proeng.2014.12.415

[10] Zedan, Y., Alkahtani, S.: Journal of Materials Processing Technology, 213, 2013, p. 167. doi:10.1016/j.jmatprotec.2012.09.007

[11] Rajinikanth, V., Venkateswarlu, K., Sen, M. K., Das, M., Alhajeri, S. N., Langdon, T. G.: Materials Science and Engineering A, 528, 2011, p. 1702. doi:10.1016/i.msea.2010.10.102

[12] Li, Y., Tan, Y., Li, J., Xu, Q., Liu, Y.: Journal of Alloys and Compounds, 583, 2014, p. 85. doi:10.1016/j.jallcom.2013.08.145

[13] Kamiya, M., Yakou, T., Sasaki, T., Nagatsuma, Y.: Materials Transactions, 49, 2008, p. 579. doi:10.2320/matertrans.MRA2008381

[14] Steininger, A., Siller, A., Bleicher, F.: Procedia Engineering, 100, 2015, p. 1124. doi:10.1016/i.proeng.2015.01.475

[15] Stephenson, D. A., Agapiou, J. S.: Metal Cutting Theory and Practice. 2nd Edition. New York, Taylor \& Francis 2006

[16] Boothroyd, G., Knight, W. A.: Fundamentals of Machining and Machine Tools. 3rd Edition. New York, Taylor \& Francis 2006.

[17] Kalpakjian, S., Schmid, S. R.: Manufacturing Engineering and Technology. Upper Saddle River, Prentice Hall 2010.

[18] Grover, M. P.: Principles of Modern Manufacturing. 4th Edition. Hoboken, John Wiley \& Sons, Inc. 2010.

[19] Black, J. T., Kohser, R. A.: Materials \& Processes in Manufacturing. 10th Edition. Hoboken, John Wiley \& Sons, Inc. 2008.

[20] Grzesik, W.: Advanced Machining Processes of Metallic Materials. Oxford, Elsevier 2008. 